\title{
Experimental Study of Exhaust Emissions of W/O Emulsion Fuel in DI Single Cylinder Diesel Engine
}

\author{
Agung Sudrajad (Corresponding author) \\ Mechanical Engineering Faculty, University of Malaysia Pahang \\ Kuala Pahang Pekan 26600 Malaysia \\ Tel: 60-9-424-2201 E-mail: sudrajad@ump.edu.my \\ Fujita Hirotsugu \\ Maritime Sciences Faculty, Kobe University \\ Kobe-shi, Higashinada-ku, Japan \\ Ismail Ali \\ Mechanical Engineering Faculty, University of Malaysia Pahang \\ Kuala Pahang Pekan 26600 Malaysia
}

Received: May 20, 2011

Accepted: June 20, 2011

doi:10.5539/mas.v5n5p73

The research is financially supported by University Research Grant of University Malaysia Pahang, Malaysia

\begin{abstract}
This research is attempted to study of diesel oil-water emulsion fuel (water in-oil type) for direct injection single cylinder diesel engine. The laboratory experimental project is using $10 \%$ water mixed with Diesel Oil (DO) and in a few of inorganic surfactant by volume ratio (10\% water, $89 \%$ diesel oil, $1 \%$ surfactant). These components are mixed in mechanical mixer controlled, to produce blending fuel. During the blending process the special surfactant will make oil surrounds the water droplet to prevent the water from separating out of the mixture. The encapsulation of water in oil in micrometer sizing is prevents the water from contacting any metal engine parts. The experimental laboratory is conducted with single cylinder diesel engine set-up at 2000 rpm with variable of engine load. Measurement of engine emissions parameters at different load conditions have generally indicated reduce in engine $\mathrm{CO}, \mathrm{NO}$ and $\mathrm{SO}_{2}$ emission as compared to base diesel oil.
\end{abstract}

Keywords: Diesel oil-water emulsion, Exhaust emission, Diesel engine

\section{Introduction}

Engine manufacturers have succeeded in developing diesel engine with high thermal efficiency and power concentration, always keeping inside the frame of complying with the imposed emission regulations that become every day more and more stringent (Obert, 1973). Nowadays, diesel engines are used in transportation, electric power generation, farming, construction and in many industrial activities. These wide fields of the usage lead to increasing requirement of petroleum derived from fuels. The other side, depleting petroleum reserves, increasing prices of the petroleum product and growing concern of the environment and the effect of greenhouse gases during the last decades, has revived an intensive search for a new alternative fuels.

Recently, the emphasis on fuel conservation and reduction of desirable emissions has generated much interest in utilizing water in oil (w/o) emulsions in conventional liquid fuelled combustor. Introduce water into combustion chamber, diesel oil emulsions appear to be the most appropriate because they require no engine retrofitting. The emulsion fuel which is mix heavy fuel oil (HFO) and water that droplet form as water in oil type was succeed studied by Javier (1995) and developed to applied in boiler by ECC corporation (Nohara, 2000) and Kim (2006). Hirotatsu W. (2010) have developed mathematical model to calculate the mass of generated water vapour at micro-explosion and Park (2000) was explained the w/o emulsions in rapid compression and expansion machine. The water in the emulsions with w/o type that is suspended in the fuel by a surfactant, thus water does not come 
into direct contact with engine surface. This type provides advantages due to enhanced in-cylinder droplet evaporation caused by droplet micro-explosion from rapid gasification of suspended water in the atomized droplets (Kadota, 2002).

Water may be added to the fuel in several ways: by stratified fuel-water injection (Miyamo et all ), or through the preparation of stabilized water/fuel emulsion (W/O) emulsion fuel, continuously into the air stream via a single point system or periodically through intake valves via a multi-point system (Samec et.all 2000). The participation of water in the evaporation process is expected to lower the droplet temperature. This results in the significant reduction of the intensity of the liquid phase pyrolytic reactions which may lead to the formation of carbonaceous residue. The reduction in the formation of carbonaceous residue is expected to be more remarkable for low volatile fuel. The dilution of water vapour would suppress the chemical reaction in the gas phase due to the reduced rate of heat release in the flame. Since the high flame temperature is usually a major source of thermal NO production. The suppressed of chemical reaction is expected to lead to the reduced flame temperature and hence the significant reduction of $\mathrm{NO}$ production.

Several emulsified fuels are commercially available and are marketed under trade names the big player companies. Abu Zaid (2004) conducted a study investigate the effect of using water fuel emulsions on the performance and gas temperature of single cylinder diesel engine. Emulsified diesel fuels of 0, 5, 10, 15 and 20 water/diesel rations by volume were used, operating was in the range 1200 to $3300 \mathrm{rpm}$. Results indicated that the addition of water in the form of emulsion improves combustion efficiency. The engine torque, power and brake thermal efficiency increase with the increase of water percentage in the emulsion.

In this paper we present measurements of the characteristic of exhaust gases of a diesel engine operating on a typical diesel oil emulsion were examined in our laboratory. Measurement and discussion on the gaseous emissions of the engine are presented with particular emphasis. The apparatus is constructed to facilitate the analysis of exhaust effluents to measure the concentration of most common exhaust species namely; $\mathrm{NO}, \mathrm{CO}$ and $\mathrm{SO}_{2}$.

\section{Materials and Methods}

Base of oil-water emulsion fuel according to the present invention is the diesel oil (DO). The emulsion fuel is water in oil type, unchangeable and oil-water separation does not occur. That is prepared by adding water (warm water) plus additive to diesel oil being a base fuel. The new mixer system was developed for the preparation of the present fuel and preferable particle size of water in oil at 20 to $30 \mu \mathrm{m}$. An emulsion takes on the characteristics of the continuous phase. Hence, fuel oil emulsions exhibit characteristic of fuel oil not water. The term of surfactant is blend of surface active agent. In this experiment, the inorganic material consist of the mixture of sodium hydroxide, calcium hydroxide and chlorine were blend into surfactant. The surfactant will reduce the surface tension of water by absorbing at the liquid-gas interface. They also reduce the interfacial tension between oil and water by absorbing at the liquid-liquid interface. Figure 1 show the schematic diagram of mixer system. Base fuel from DO tank is conduct to the mixer by control of volume and pressure. Water and additive controlled by pump transfer to the mixer. The static spiral mixer type used to make emulsion fuel.

A direct-injection diesel engine (model TF120 YANMAR) one cylinder, capacity of 12HP was employed to the test. It is water cooled and connected with hydraulic dynamometer. The engine specification is shown in table 1. The engine experimental work on four-stroke cycle and was operated at $2000 \mathrm{rpm}$ with 25,50 , and $75 \%$ engine load. A hydraulic dynamometer was used to adjust the engine load. The engine load was controlled by the control panel. The experiment by two kind of fuel as $100 \%$ DO and $10 \%$ emulsion $(89 \%$ volume DO $+10 \%$ water $+1 \%$ surfactant) were conducted in the present work. Exhaust gas temperature was measured using a thermocouple located downstream of the exhaust valve. Figure 2 show the diagram of experimental engine setup. The exhaust gases were analyzed by $\mathrm{NO}, \mathrm{SO}_{2}, \mathrm{O}_{2}, \mathrm{CO}$, analyzer. The test were conducted and repeated five times for every kind of fuel, in order to increase the reliability of the test results.

\section{Results and Discussions}

Nitrogen oxides emissions are predominately temperature phenomena, the presence of oxygen increase the heat release rate for the oxygenated fuel and hence the NO emission will be high. Comparing two kind of fuel, the burning of oil- water emulsions emitted significantly less NO than the diesel oil. Figure 3 show the NO emission concentration, NO concentration was decrease from $340 \mathrm{ppm}$ to $280 \mathrm{ppm}$ at $25 \%$ engine load. Generally, decreasing of $\mathrm{NO}$ emission using emulsion fuel is $10 \%$ in rate for 25,50 and $75 \%$ engine load. This is because the water contents of the emulsion causes a heat sink phenomenon. When heat sink occur it results in water content of the inner phase partially absorbing the calorific heating value of the emulsions, thereby decreasing the 
burning gas temperature inside the combustion chamber thus restraining the generation of NO (Stephen, 2000). A minor contribution to the $\mathrm{NO}$ formation may also be expected by considering the following reactions:

$$
\begin{aligned}
& \mathrm{O}+\mathrm{N}_{2}+\mathrm{M}=\mathrm{N}_{2} \mathrm{O}+\mathrm{M} \\
& \mathrm{N}_{2} \mathrm{O}+\mathrm{O}=2 \mathrm{NO}
\end{aligned}
$$

which may become important at lower temperatures because of their lower activation energy, especially for reaction (2). Additionally, the NO concentration may be reduced by reducing the $\mathrm{O}$ atoms concentration due to its consumption at the $\mathrm{OH}$ radicals formation by the following reactions:

$$
\begin{aligned}
& \mathrm{H}_{2} \mathrm{O}+\mathrm{O}=\mathrm{OH}+\mathrm{OH} \\
& \mathrm{H}_{2} \mathrm{O}+\mathrm{H}=\mathrm{OH}+\mathrm{H}_{2}
\end{aligned}
$$

as a consequence of the water present in the fuel.

The latent heat of water will cool the charge due to the evaporation of water, and the cylinder average temperature following injection and before ignition becomes lower as the water percentage increases. This results in lower peak combustion temperature. As shown in the figure 4, the $\mathrm{CO}$ emissions were decreased when using emulsion fuel. The formula for calculating $\mathrm{CO}$ oxygenating rate $\mathrm{K}_{\mathrm{CO}}$ is : $\mathrm{CO}+\mathrm{OH} \dashv \mathrm{CO}_{2}+\mathrm{H}, \mathrm{K}_{\mathrm{CO}}=$ $6.76 \mathrm{x} 10^{10} \exp [\mathrm{T} / 1102] \mathrm{cm}^{3} / \mathrm{gmol}$, according to this formula when the temperature $\mathrm{T}$ lower, the $\mathrm{CO}$ oxygenation rate lower too as decreasing of $\mathrm{CO}$ in this experiment. Also effect of adding water in the fuel will increase of oxygen availability in the fuel, its will effect on lower f CO emissions.

Figure 5 show the variations of $\mathrm{SO}_{2}$ emissions for the diesel oil and the emulsion fuel. Both the fuel has the capacity to increase $\mathrm{SO}_{2}$ emissions by increase of engine load. The variation in amount of increasing depends on the availability of the amount of sulphur irrespective of its chemical structure. The increasing of $\mathrm{SO}_{2}$ emissions were high at $50 \%$ and $75 \%$ engine load compare to the $25 \%$ engine load.

When adding amount of water ( $10 \%$ water by volume) to the fuel, the corresponding amount of fuel is replaced by water resulting in lower combustion temperature as shown in figure 6 . The evaporation and additional mass of water effect to the cylinder average temperature to become lower. The variations of the gases exhaust temperature by engine load for the different fuel shown in figure 6. Exhaust gas temperature shown decreasing because of carbon content in the exhaust gas with emulsion fuel is low. Exhaust gas temperature was slightly decreased from 290 to $270^{\circ} \mathrm{C}, 390$ to $360^{\circ} \mathrm{C}$, and 530 to $510^{\circ} \mathrm{C}$ at $25 \%, 50 \%$ and $75 \%$ engine load, respectively.

The stoichiometric air requirement for the combustion of emulsion is lower, since they already contain oxygen in its structure, hence larger amount of fuel can be burnt in a given amount of air and hence the fuel consumption decreases for the emulsion fuel compared with diesel oil as shown in figure 7. From the figure, it is observed that addition of water in diesel oil reduce the fuel consumption due to the availability of more oxygen. The reduction fuel consumption with water emulsified diesel may be attributed to formation of a finer spray due to rapid evaporation in the water, longer ignition delay results in more fuel burning in premixed combustion and suppression of thermal dissociation due to lower cylinder average temperature.

\section{Conclusions}

Experimental study of single cylinder diesel emissions by using w/o emulsion fuel has been examined. Emissions of $\mathrm{NO}$ and $\mathrm{SO}_{2}$ concentration by emulsion fuel are lower than base diesel oil. Effect of adding water in the oil give results on high oxygen contain in the fuel, hence larger amount of fuel can burnt in a given lower fuel consumption. Moreover reduce of sulfur content in the fuel caused by adding water, give results in decreasing of $\mathrm{SO}_{2}$. The results from experiments prove that w/o emulsions fuel potentially good alternative fuels for diesel engine in the near future because of give a benefit effect on the fuel oil consumption and reduction of pollutants emissions.

\section{References}

Abu Zaid. (2004). Performance of single cylinder, direct injection diesel engine using water fuel emulsions. Energy Conversion and Management 45(2004);697-705. doi:10.1016/S0196-8904(03)00179-1, http://dx.doi.org/10.1016/S0196-8904(03)00179-1

Javier, Norberdo, Cesar, (1995). Combustion Characteristic of Heavy Oil Water Emulsions, Fuel vol. 75 no.6:695-705.

Kadota T, Yamasaki H. (2002). Recent advances in the combustion of water fuel emulsion. Prog Energy combustion Science 2002;28:385-404 
Hirotatsu watanabe et all. (2010). An experimental investigation of the breakup characteristics of secondary atomization of emulsified fuel droplet. Energy 35 (2010) 806-813. doi:10.1016/j.energy.2009.08.021, http://dx.doi.org/10.1016/j.energy.2009.08.021

Kim Houng Soo, Takehiro Murakami, Osami Nishida, Hirotsugu Fujita, Wataru Harano, Hirotsugu Nohara, (2006). PM Formation-Decomposition and Combustion Characteristic of Heavy Fuel Emulson Oil, Journal of JIME Vol. 41 No. 3 2006, Japan.

Miyamo H, Yasueda S, Tayama K, Tabeishi M, Tosa Y, Nagoe Y. Development of stratified fuel-water injection system for low-NOx diesel combustion. Proceeding of SAED24.

Nohara H. (2000). Water Oil Emulsion Fuel, US Patent No. 6,296,676 B,

Obert EF. (1973). Internal Combustion Engine and air pollution. New York: Intext Education Publ.

Park J.W, Huh K.Y, Park K.H, (2000). Experimental study on combustion of emulsified diesel in a RCEM, World Automotive Congress 2000, F 2000A073, Korea.

Samec N, Dibble RW, Chen JY, Pagon A. (2000). Reduction of NOx and soot emission by water injection during combustion in a diesel engine. Proceeding of FISITA2000,Seoul,Korea;

Samec N, Dibble RW. (2000). The strategies for reducing emission from Heavy duty diesel vehicles. Proceeding of UrbanTransport 2000, Cambridge,UK;

Stephen R Turn, (2000). An Introduction to Combustion Concept and Application, Mc Graw Hill. USA.

Table 1. Experimental Engine Specification

\begin{tabular}{ll}
\hline Engine Type & YANMAR TF120 \\
\hline Number of Cylinder & 1 \\
Bore x stroke (mm) & $92 \times 96$ \\
Displacement (L) & 0.638 \\
\hline Continuous Output (HP) & $10.5 \mathrm{HP}$ at $2400 \mathrm{rpm}$ \\
Rated output (HP) & $12 \mathrm{HP}$ at $2400 \mathrm{rpm}$ \\
\hline Cooling system & Water \\
\hline Dry weight (kg) & 102 \\
\hline
\end{tabular}




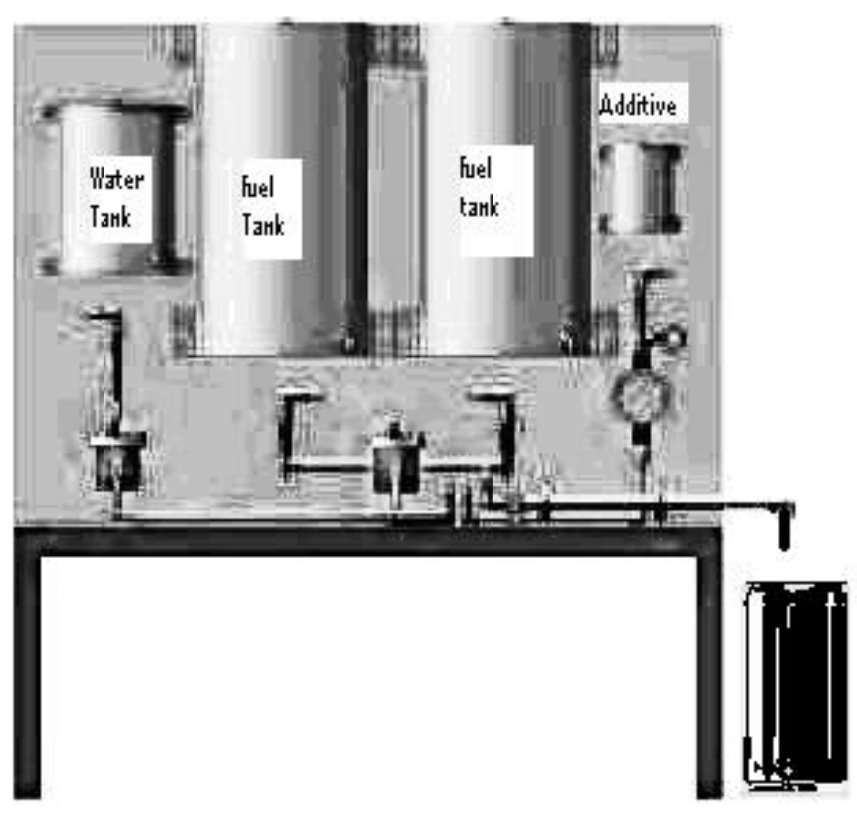

Figure 1. the W/O mixer schematic diagram

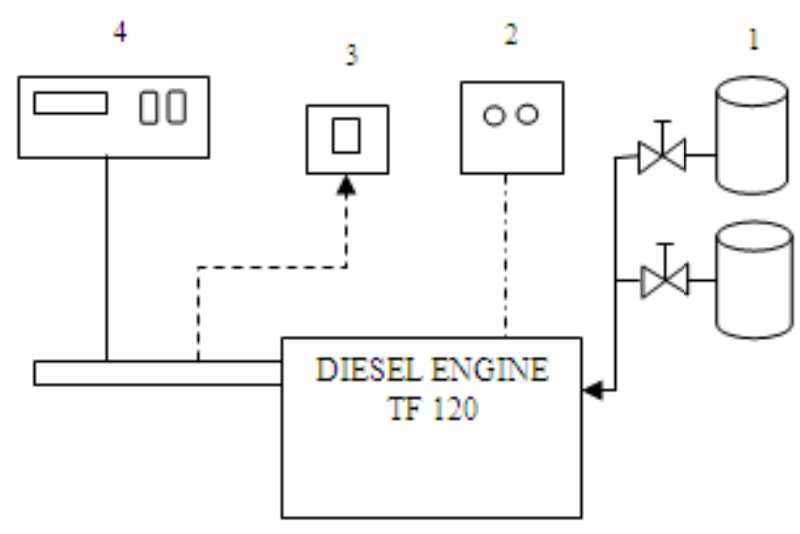

1.Fuel Tank, 2.Load Control, 3.Thermocouple, 4.CO/O $/ 2 / \mathrm{NO} / \mathrm{SO}_{2}$ Analyzer,

Figure 2. the experimental setup 


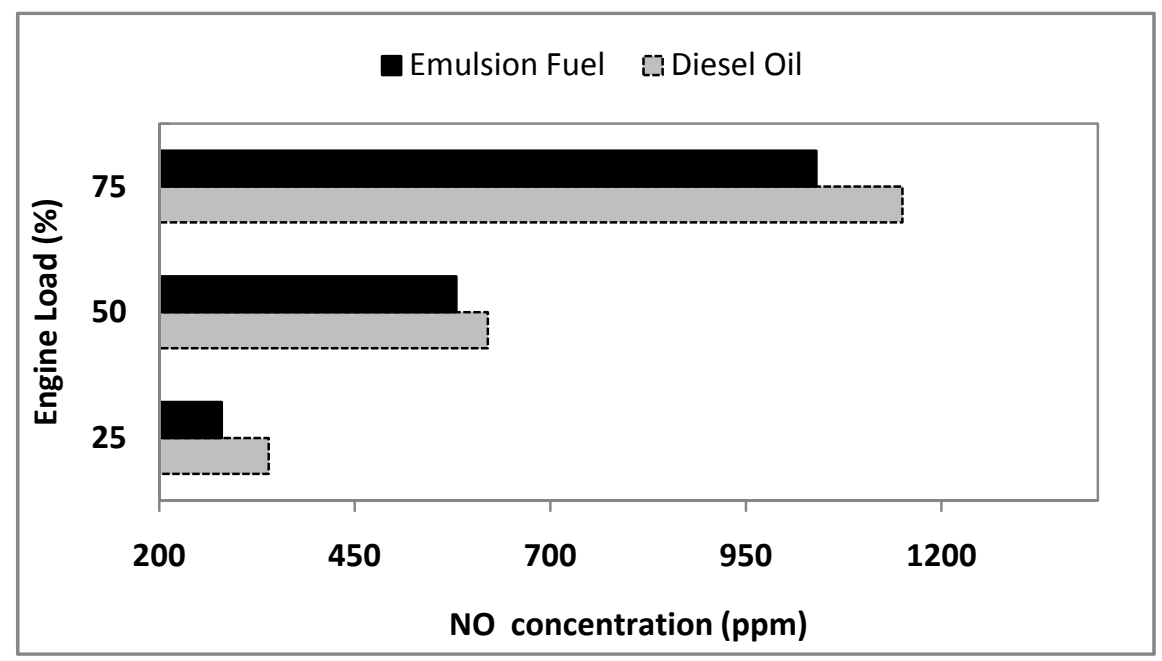

Figure 3. NO emission concentration

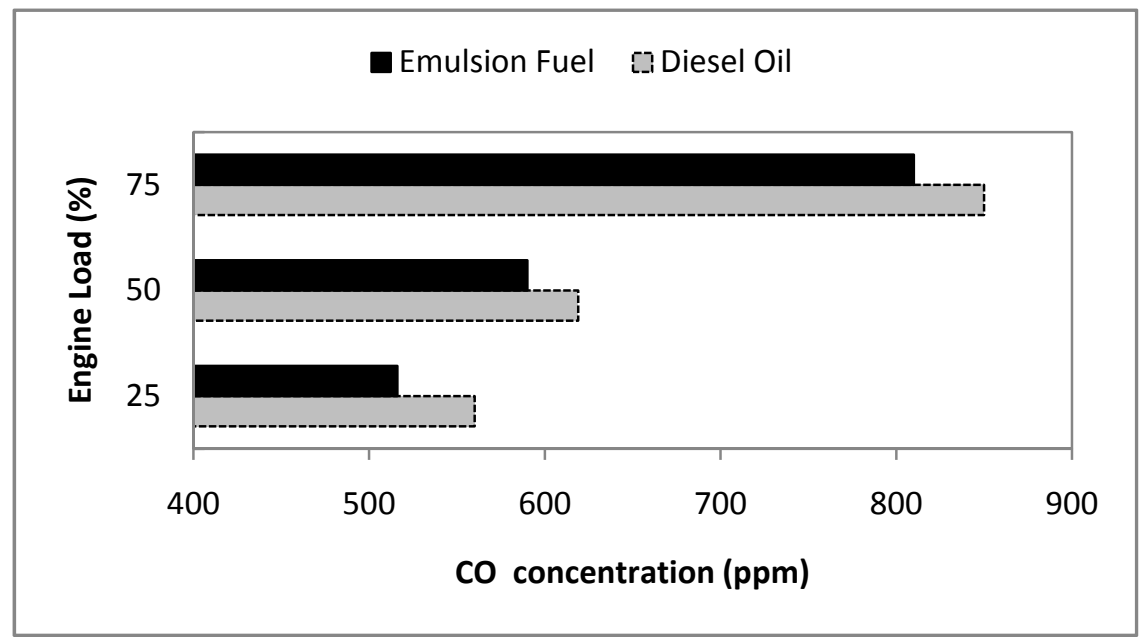

Figure 4. $\mathrm{CO}$ emission concentration

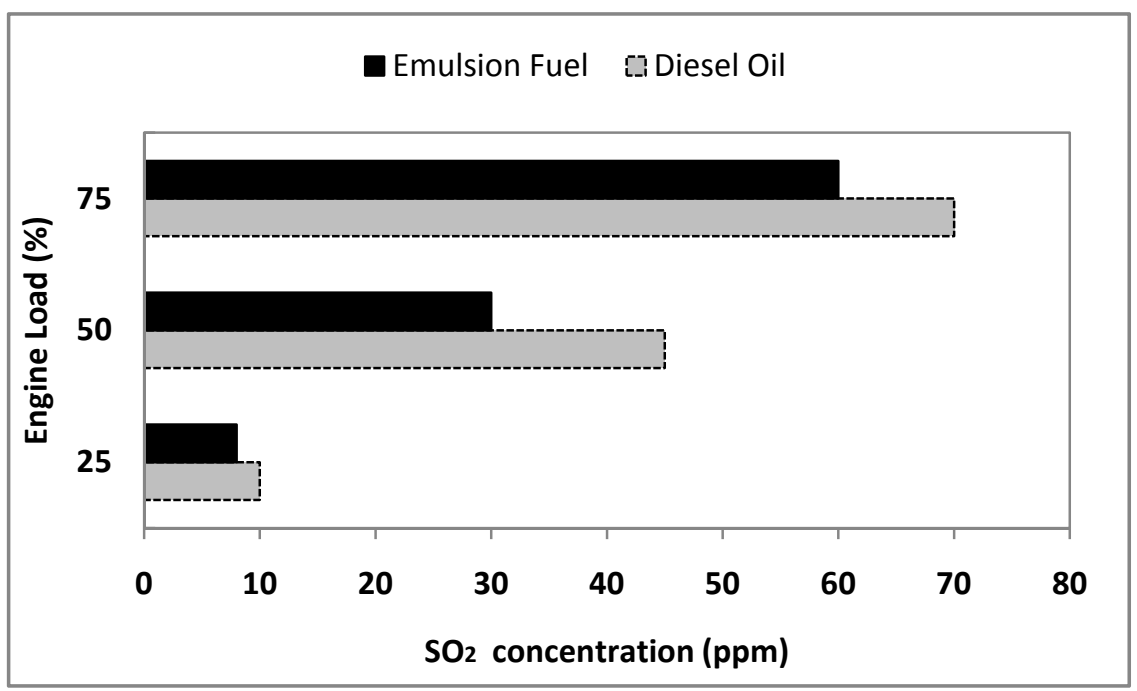

Figure 5. $\mathrm{SO}_{2}$ emission concentration 


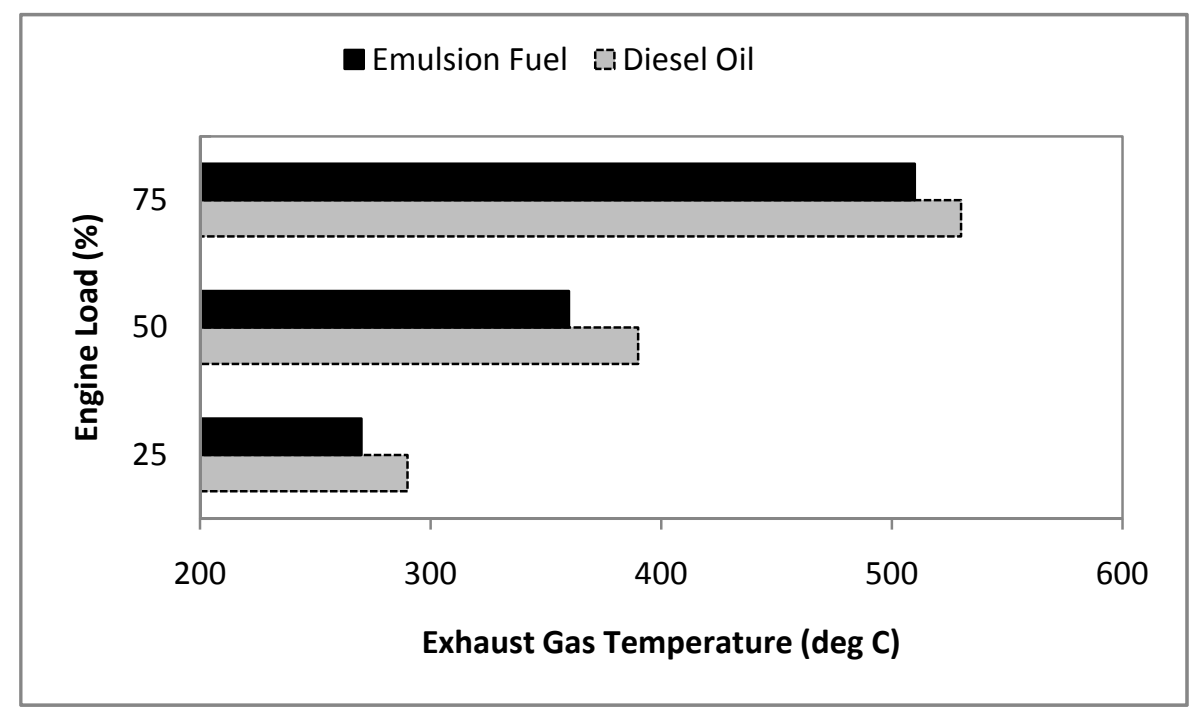

Figure 6. the exhaust gas temperature

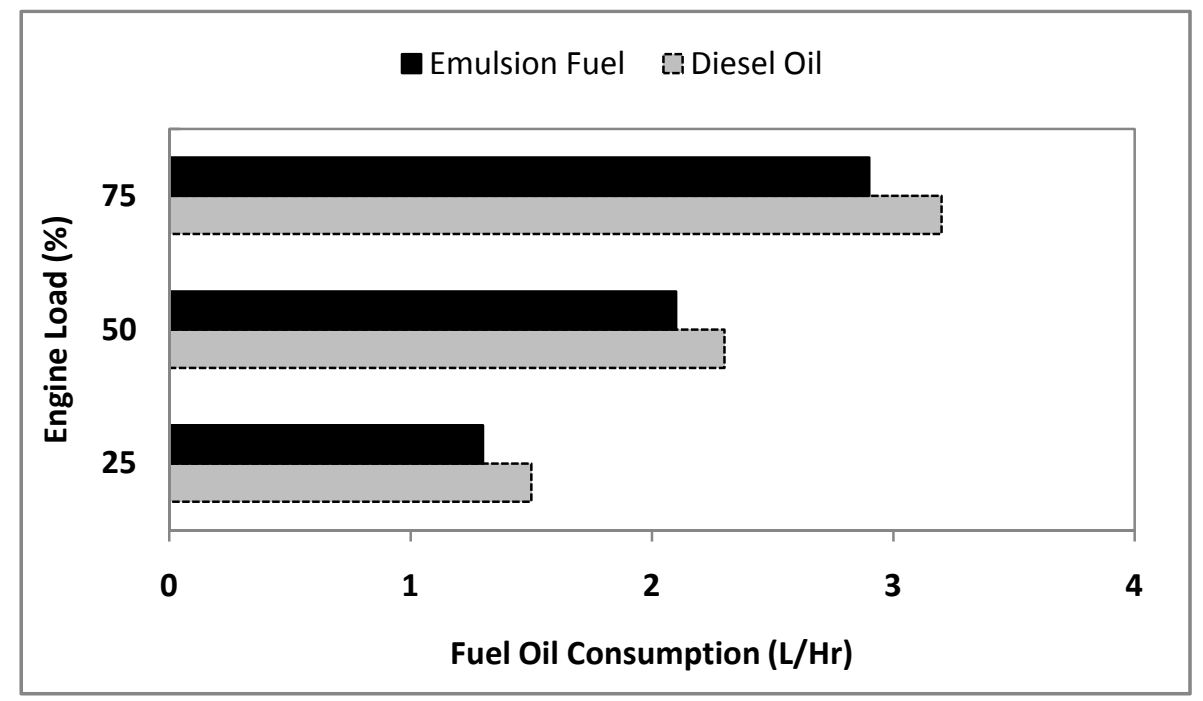

Figure 7. the fuel oil consumption 